\title{
PSYCHE.
}

\section{CONTRIBUTION TO THE KNOWLEDGE OF SONIFACTION IN INSECTS.}

\author{
BY OSKAR PAUL KRANCHER, LEIPZIG, GERMANY.
}

In my rearing of Saturnia pyri, this year (1882), I had the pleasure of making an observation which was entirely new to me and which, in my opinion, the literature of the subject, up to the present time, does not mention. It was that after the larvae of the above-mentioned moth had passed their last molt, - the molt in which the violet tubercles that clothe the whole body are changed into the well-known sky-blue ones adorned with a stelliform covering of hairs, - and were almost full-grown, I was astonished to find that they were suddenly able to produce a peculiar noise. Whenever I came near them and still more when I touched them, I heard a sort of grating, perhaps more correctly a whurring, which was not unlike the guttural, non-vocal rattling of $r$, and which has been observed in a kindred way in certain beetles. This sound can best be imitated artificially by drawing a little stick or perhaps a wire, not too quickly over a grooved surface.

For lack of time I could not determine then how this sound was produced, but I think I am not mistaken in supposing that it is produced near the mouth-parts, if not by those organs. It appears to me almost as if the above-mentioned whurring might be considered a sort of cry, one might almost say a scolding, since the larva, even upon the slightest touch, not rarely jerks the whole anterior part of its body in the most forcible manner, from one side to the other, at the same time producing the whurring sound. The slightest irritation also is followed by this whurring. But I always observed that the larva drew in its head more or less, according as the sound lasted for a greater or less length of time, of course only while the sound was being produced.

When I communicated this observation at a June meeting of the entomological society here it appeared that the facts were not known, up to that time, to any of the persons present, which has induced me to publish this note. I hope I shall soon succeed in rearing a new brood of $S$ pyri, in order to carry my observations further. I may remark, further, that I obtained, in this year's breeding, 19 larvae from 20 eggs, and from these larvae 16 pupae, from which I hope to obtain the moths next spring.

Permit me at the same time to notice here two other interesting items. Last 
year (1881) Mr. Brabandt reared the larvae of Stauropus fagi (called the crabcaterpillar on account of its shape) which larvae, as is well-known, always quarrel with each other and are fond of biting off each other's front-legs. Under such circumstances Mr. Brabandt obtained a larva which had lost one of its long forelegs in a contest, but this appeared to disturb the insect little; and it continued feeding unconcernedly and pupated; and, on 5 June of this year, the moth emerged. The moth showed only the single defect of not possessing the leg corresponding to the one which the larva had lost.

The following may serve as a contribution to the subject of the fertility of lepidoptera. Mr. Brabandt obtained from a chrysalis, this spring, a female Lasiocampa quercifolia. As it was crippled he decided to set it out of doors in order perchance to attract a male, or in other words to secure a fertilization. Luck favored him; the next morning he found the female, only a few steps distant, in copulation with a male. The latter, in fine condition, was spread, but the female was imprisoned for the purpose of obtaining eggs. Behold! she did her duty in the most thorough way, for during the first night she laid no less than 510 eggs, and during the second night 70 more, - a total of 580 eggs, a fecundity on the part of a lepidopteron which is remarkable, and very rarely recorded. Not a single egg was abortive, and each one hatched its young larva.

Leipzig, 10 Aug. 1882.

\section{ON A LARVA BORING THE LEAF-STALKS OF THE BUCKEYE ( $A E S C U L U S$ GLABRA) IN OHIO.}

BY EDWARD WALLER CLAYPOLE, NEW BLOOMFIELD, PERRY CO., PA.

Several years ago, soon after going to reside at Yellow Springs, Ohio, I noticed, in the early part of May, that many of the leaves of the Ohio buckeye, Aesculus glabra, drooped and withered very soon after they had unfolded from the bud. For two or three years these drooping leaves caught my attention. On gathering them I uniformly found a small hole in the leaf-stalk, from which a tunnel, sometimes twelve millimetres in length, ran along the stalk. Above this hole the leaf was dying, below it the stalk was still alive. In some few instances I found in the tunnel a small yellowish caterpillar, evidently the author of the mischief. Wherever the hole in the stalk was closed with droppings the caterpillar was present, but whenever the hole was open the caterpillar was gone, leading to the inference that.it had escaped through the opening.

After having made these preliminary notes I attempted, in May 1878, to trace out the life-history of this insect, but, being very much pressed with work, the experiment was a failure. The leaves were overlooked for a few days of warm weather, became mouldy, and the caterpillars died.

In 1879 I made a second attempt with rather better success, but still without result 

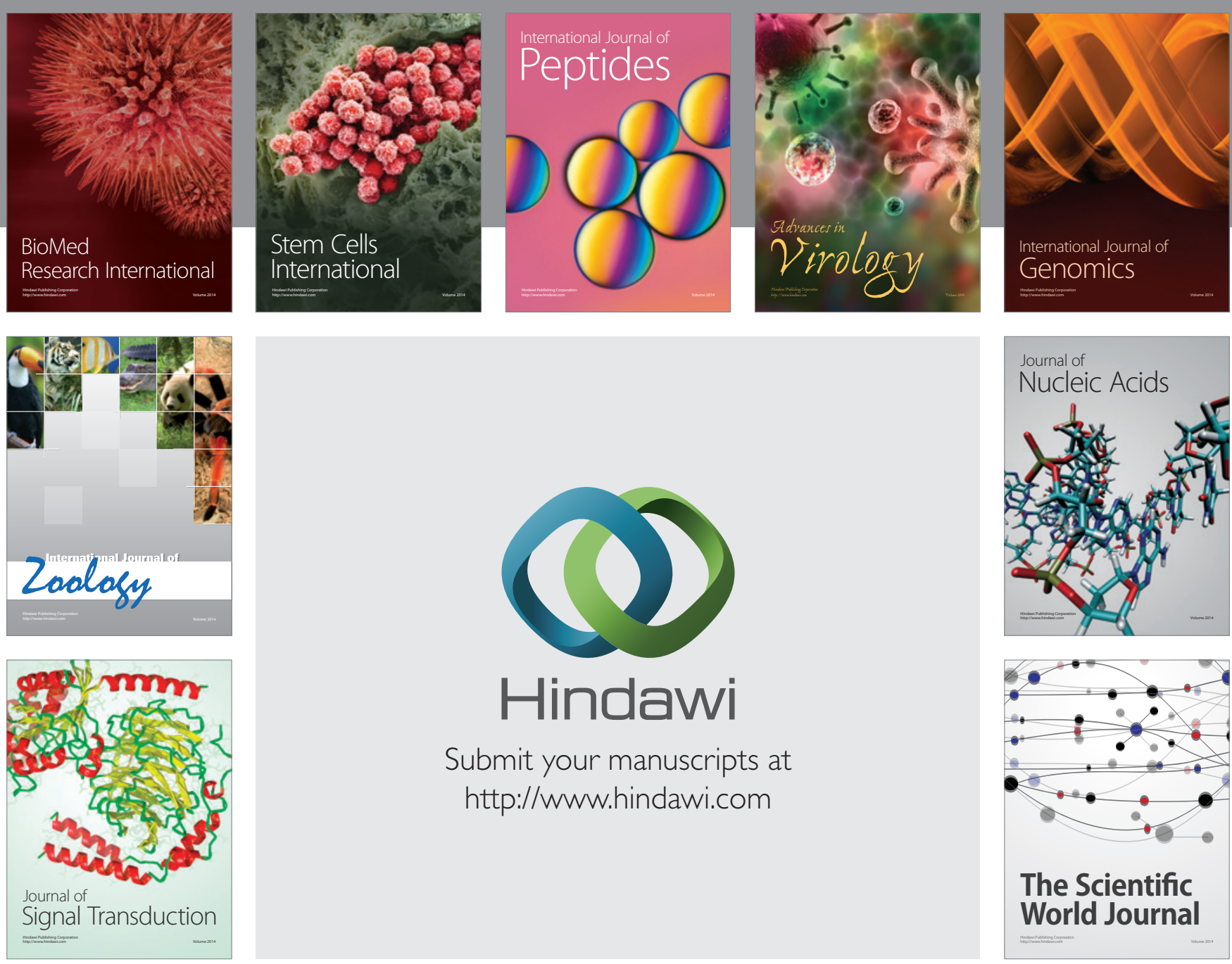

Submit your manuscripts at

http://www.hindawi.com
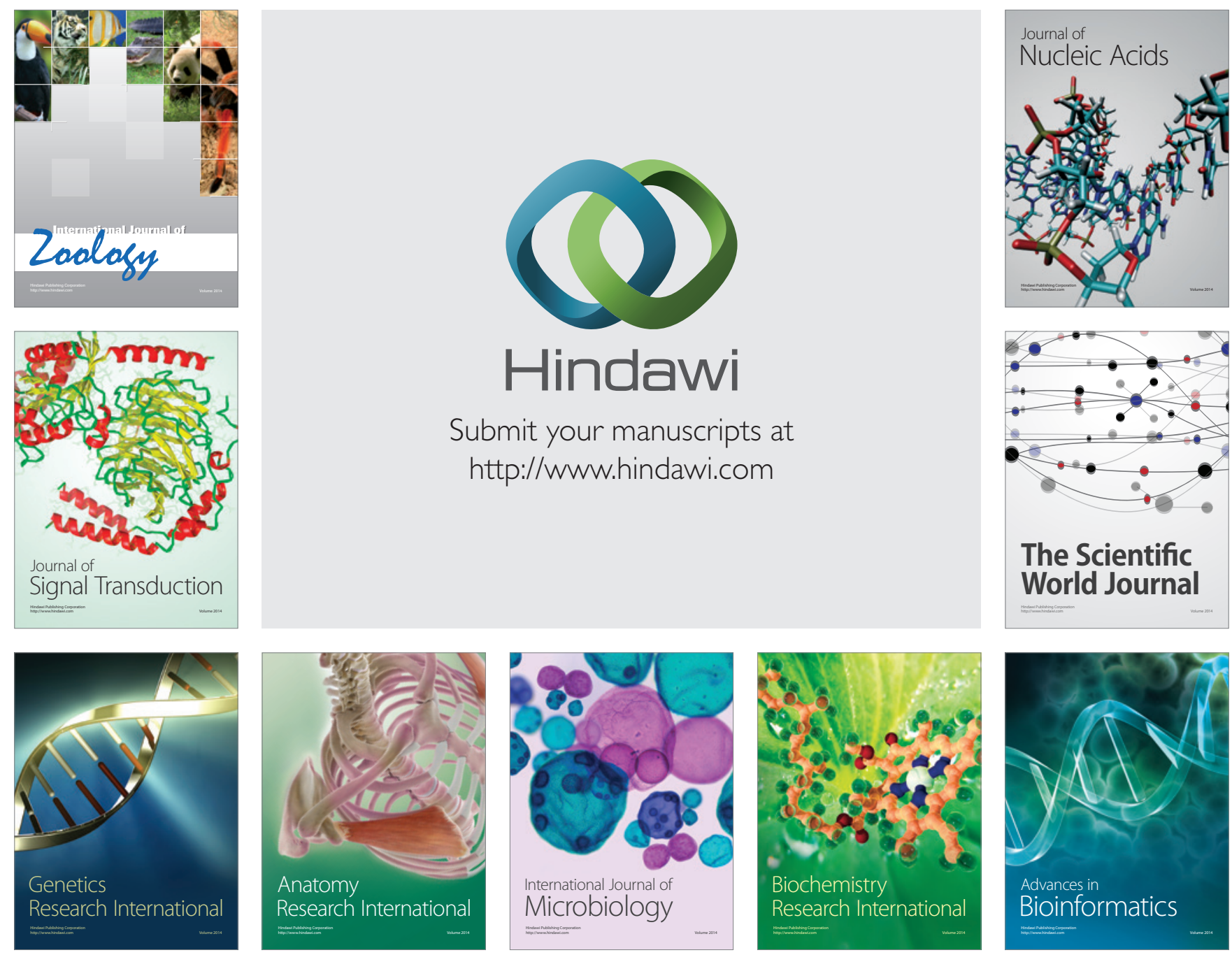

The Scientific World Journal
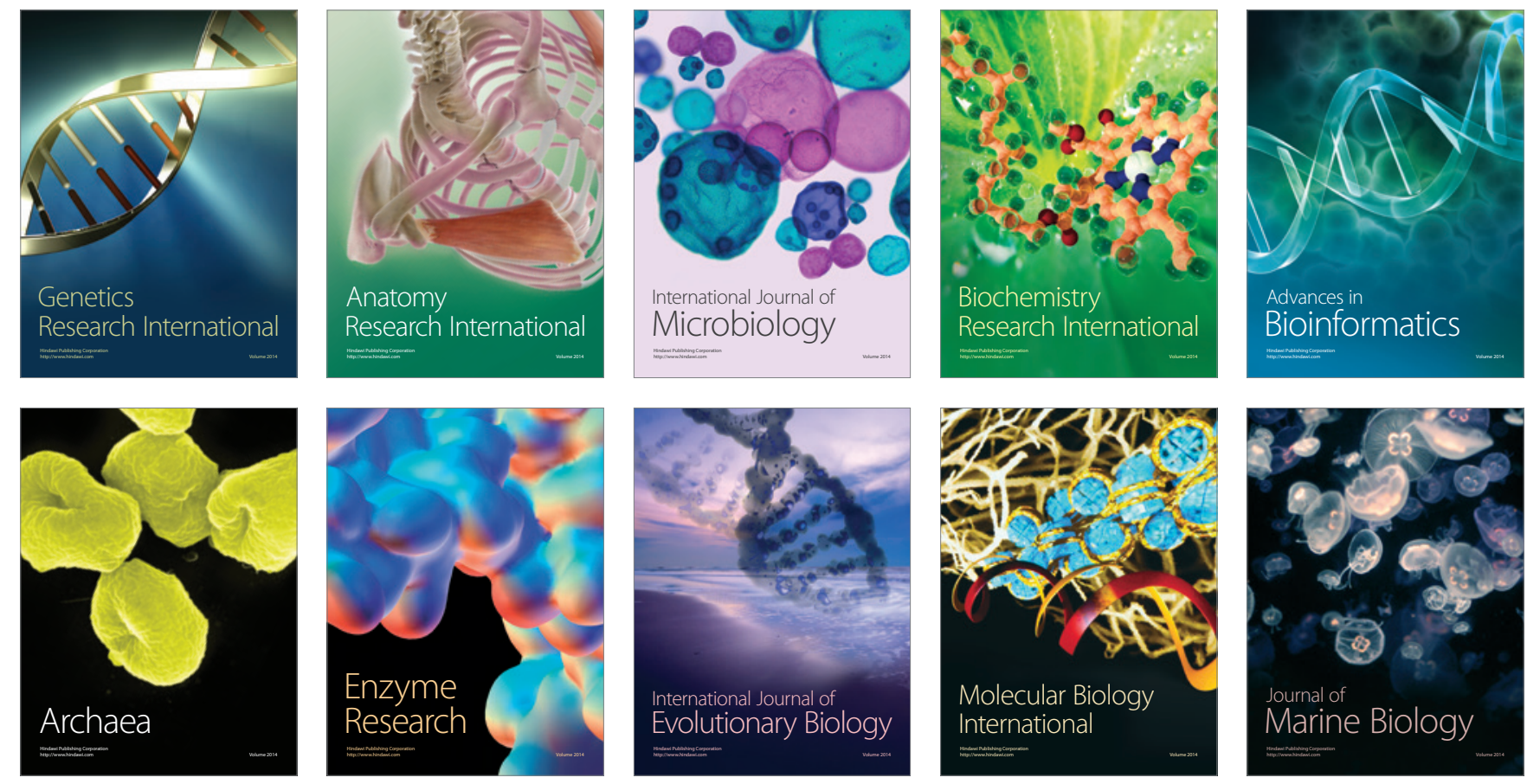